\title{
OS TEMAS DA EVOLUÇÃO E DO PROGRESSO NOS DISCURSOS DA PSICOLOGIA EDUCACIONAL E DA HISTÓRIA DA EDUCAÇÃO
}

\author{
Ana Laura Godinho Lima
}

\section{RESUMO}

$\mathrm{O}$ artigo consiste em uma análise de um conjunto de manuais de psicologia educacional e história da educação destinados à formação docente, cujo objetivo é identificar as aproximações e os distanciamentos entre essas disciplinas no que se refere à presença dos temas da evolução e do progresso. A análise incide sobre manuais publicados no Brasil entre 1934 e 1972 e inspira-se nos escritos de Foucault sobre a análise do discurso. Nos manuais dessas disciplinas, observouse a recorrência da associação entre o desenvolvimento da criança e do progresso social, frequentemente descritos à luz da teoria da recapitulação. Essa teoria não foi, contudo, objeto de consenso, mas constituiu foco de controvérsia, representando um aspecto do debate entre educadores escolanovistas e católicos no período considerado.

Palavras-chave: evolucionismo, progresso, psicologia educacional, manuais de ensino, formação docente.

${ }^{1}$ Universidade de São Paulo (USP) São Paulo/SP, Brasil. 


\title{
LOS TEMAS DE LAEVOLUCIÓN Y DEL PROGRESO EN LOS DISCURSOS DE LA PSICOLOGÍA EDUCACIONAL Y DE LA HISTORIA DE LA EDUCACIÓN.
}

\section{RESÚMEN}

El artículo consiste en un análisis de un conjunto de manuales de psicología educativa e historia de la educación destinados a la formación docente, cuyo objetivo es identificar las aproximaciones y los distanciamientos entre esas disciplinas en lo que se refiere a la presencia de los temas de la evolución y del progreso. El análisis incide sobre manuales publicados en Brasil entre 1934 y 1972 y está inspirado a los escritos de Foucault sobre el análisis del discurso. En los manuales de estas disciplinas, se observó la recurrencia de la asociación entre el desarrollo del niño y del progreso social, a menudo descritos a la luz de la teoría de la recapitulación. Esta teoría no fue, sin embargo, objeto de consenso, pero constituyó un foco de controversia, representando un aspecto del debate entre educadores escolanovistas y católicos en el período considerado.

Palabras-clave: evolucionismo, psicología educacional, progreso, manuales de enseñanza, formación docente.

\section{THE THEMES OF EVOLUTION AND PROGRESS IN THE DISCOURSES OF THE EDUCATIONAL PSYCHOLOGY AND THE HISTORY OF EDUCATION.}

\begin{abstract}
The article consists of an analysis of a set of textbooks of educational psychology and history of education aimed at teacher education, whose objective is to identify the approximations and distances between these disciplines with respect to the presence of the themes of evolution and progress. It focuses on manuals published in Brazil between 1934 and 1972 and is inspired by Foucault's writings on discourse analysis. In the textbooks of these disciplines, it was observed the recurrence of the association between the child development and the social progress, often described in the light of recapitulation theory. This theory was not, however, the object of consensus, but it was a focus of controversy, representing one aspect of the debate between representatives of the New School movement and Catholic educators during the period considered.
\end{abstract}

Keywords: evolutionism, educational psychology, progress, teaching manuals, teacher training.

\section{LES THÈMES DE L'ÉVOLUTION ET DU PROGRÈS DANS LES DISCOURS DE LAPSYCHOLOGIE ÉDUCATIVE ET LA HISTOIRE DE L'ÉDUCATION}

RESUMÉ 
L'article consiste en une analyse d'un ensemble de manuels de psychologie de l'éducation et d'histoire de l'éducation destinés à la formation des enseignants, dont l'objectif est d'identifier les approximations et les distances entre ces disciplines par rapport à la présence des thèmes de l'évolution et du progrès. Il se concentre sur les manuels publiés au Brésil entre 1934 et 1972 et s'inspire des écrits de Foucault sur l'analyse dudiscours. Dans les manuels de ces disciplines, nous avons observé la récurrence de l'association entre le développement de l'enfant et du progrès social, souvent décrite à la lumière de la théorie de la récapitulation. Cette théorie n'a cependant pas fait l'objet d'un consensus, mais elle a fait l'objet d'une controverse, représentant un aspect du débat entre representatives du movement de l'École Nouvelle et les educateurs catholiques dans la période considérée.

Mots-clés: évolutionnisme, psychologie de l'éducation, progrès, manuels d'enseignement, formation des enseignants. 


\section{MODERNIZAÇÃO E PROGRESSO DA ESCOLA REPUBLICANA}

O processo de difusão mundial da escola de massas, na passagem do século XIX para o século XX, caracterizou-se pela criação e progressiva expansão das escolas seriadas onde se praticava o ensino simultâneo, modalidade na qual um professor levava uma turma de alunos da mesma faixa etária a percorrer o currículo oficial, que deveria ser seguido pelo conjunto das escolas. Caracterizou-se ainda pela tentativa dos governantes de estruturar a formação docente no âmbito das escolas normais, por meio da instituição de programas de ensino e da construção de prédios adequados, associados a escolas modelo para o aprendizado da prática. Como instituição pública encarregada de transmitir conhecimentos e formar as novas gerações, a escola passou a representar a modernidade e o progresso.

No Brasil, esse processo coincidiu com a Primeira República e teve como modelo a reforma do ensino realizada em São Paulo por Caetano de Campos, que não poupou esforços para promover a modernização da formação docente. Em 1894, inaugurou a Escola Normal da Praça, acompanhada da Escola Modelo para o aprendizado das práticas de ensino, importou materiais didáticos e trouxe professores estrangeiros para ensinar às normalistas os novos métodos. Como observou a propósito Marta Carvalho, "Educar era a aspiração uníssona que se levantava em todos os países. Não bastava, contudo, ensinar: era preciso saber ensinar" (1989, p. 26).

Contudo, as primeiras iniciativas republicanas no campo educacional não chegaram a alcançar as expectativas de seus idealizadores. Na década de 1920, os intelectuais que se dedicaram ao exame da questão constatavam a situação de atraso em que o país permanecia, o problema do analfabetismo e da falta de organização do trabalho, cuja expressão mais evidente era a população que migrava da zona rural para a urbana, transformando-se numa massa de analfabetos, pobres e doentes que vagavam pelas cidades, sem trabalho fixo, vivendo em condições miseráveis. Para a superação desse quadro desolador, 
mais uma vez a difusão da escola aparecia como solução à vista. Nos discursos da Associação Brasileira de Educação (ABE), que reunia a elite intelectual interessada na superação dos problemas nacionais,

O presente é reiteradamente condenado e lastimado, sendo caracterizado de modo a fundamentar temores de catástrofes iminentes, que atingirão o país se a campanha educacional não obtiver os resultados desejados. Ao futuro insistentemente se alude como dependente de uma política educacional: futuro de glórias ou de pesadelos, na dependência da ação diretora de uma elite que direcione, pela educação, o processo de transformação do país. (CARVALHO, 1989, p. 55).

No início dos anos 1930, com o Estado Novo e a criação do Ministério da Educação e Saúde, os debates se intensificaram, transformando-se em disputas pelo controle dos fins e dos meios da educação no país. No interior da $\mathrm{ABE}$, as discussões tornaram-se polarizadas, opondo o grupo dos educadores católicos ao dos autointitulados pioneiros da educação nova. Em 1931, realizouse a IV Conferência Nacional de Educação, aberta por Getúlio Vargas e o recém empossado ministro Francisco Campos, que convocaram os educadores a propor o conceito de educação e as ações que deveriam orientar a nova política educacional. $\mathrm{O}$ evento culminou com uma cisão que levou à saída dos católicos da ABE para fundar uma nova organização, a Confederação Católica Brasileira de Educação e, do outro lado, à elaboração do Manifesto dos Pioneiros da Educação Nova, redigido por Fernando de Azevedo (VIDAL, 2013, p. 582-583).

O Manifesto, dirigido ao povo e ao governo, apresentava um caráter simultaneamente diagnóstico e programático. Efeito das discussões dos anos 1920 sobre a dívida republicana (CARVALHO, 1989), acusava a "inorganização" do sistema educacional, consequência da dispersão das iniciativas e da falta de clareza acerca dos fins e dos meios da educação. Defendia a renovação da escola, com vistas a acompanhar o progresso científico e técnico da civilização e recomendava a reorganização do sistema de ensino e a atualização, cientificamente fundamentada, das práticas escolares. Na Escola 
Nova idealizada pelo manifesto, as práticas e os programas de ensino não atenderiam à lógica do adulto, mas à psicologia do aluno. No texto do Manifesto, o desenvolvimento do aluno associava-se ao progresso social, e ambos dependiam da adequada reorganização do sistema de ensino. Recaía sobre a escola, instituição encarregada da formação das novas gerações de trabalhadores e cidadãos, a responsabilidade pelo destino da pátria, como expressam as palavras finais do Manifesto:

(...) de todos os deveres que se incumbe ao Estado, o que exige maior capacidade de dedicação e justifica maior soma de sacrifícios; aquele com que não é possível transigir sem a perda irreparável de algumas gerações; aquele em cujo cumprimento os erros praticados se projetam mais longe nas suas consequências, agravando-se à medida que recuam no tempo; o dever mais alto, mais penoso e mais grave é, decerto, o da educação que, dando ao povo a consciência de si mesmo e de seus destinos e a força para afirmar-se e realizá-los, entretém, cultiva e perpetua a identidade da consciência nacional, na sua comunhão íntima com a consciência humana (MANIFESTO, 1932, p. $65)$.

Este texto busca caracterizar essa associação entre desenvolvimento do indivíduo e progresso social em duas disciplinas do currículo de formação dos professores, a história da educação e a psicologia educacional. $\mathrm{O}$ artigo tem como objetivo identificar as aproximações e os distanciamentos entre essas disciplinas no que se refere à presença dos temas da evolução e do progresso. Consiste em uma análise de um conjunto de seis manuais de psicologia educacional e seis de história da educação destinados à formação docente, publicados no Brasil entre 1934 e 1972, período em que se intensificou a difusão dos princípios da Escola Nova no país e os discursos em defesa da renovação do ensino cientificamente fundamentada. Recorre à produção acadêmica contemporânea sobre a história da educação aproximada da história cultural, que descreve as circunstâncias históricas nas quais se formaram os objetos, as práticas e os discursos que se tornaram tão familiares em um certo período e em um dado contexto a ponto de serem tomados como naturais ou universais. Tal 
perspectiva renuncia ao pressuposto de uma história linear e aos princípios de totalidade e de continuidade e desafia as ideias de evolução e progresso que caracterizaram o discurso pedagógico no período considerado. Reconhece, ainda, as especificidades da cultura escolar, considerada como um conjunto de objetos, discursos e práticas que apresenta configuração e objetivos próprios, embora se relacione com outras configurações. $\mathrm{O}$ exame dos manuais inspira-se na análise do discurso, tal como sugerida nos escritos de Foucault, para quem as formações discursivas correspondem a conjuntos de enunciados a propósito dos quais se pode dizer que se caracterizam por seguirem as mesmas regras no que diz respeito à formação dos objetos, dos modos de enunciação, dos conceitos e dos temas e teorias de que tratam. O discurso é assim considerado como uma prática regulada, a qual, ao mesmo tempo em que abre um conjunto de possibilidades, estabelece limites ao que pode ser dito.

No discurso da psicologia educacional, o desenvolvimento da criança foi frequentemente descrito à luz da teoria biológica da recapitulação, formulada pelo embriologista Ernest Haeckel na segunda metade do século XIX e difundida nas décadas seguintes no campo das ciências humanas, principalmente por intermédio das obras de Herbert Spencer. De acordo com essa teoria, "a ontogênese reproduz a filogênese", ou seja, cada indivíduo percorre em seu desenvolvimento as etapas de evolução da humanidade. Podese dizer que a teoria da recapitulação constituiu um modo de entrada no discurso, ou, nas palavras de Foucault, uma estratégia para a formação de enunciados que associavam as mudanças vividas pelas crianças em seu crescimento às transformações históricas ocorridas nas sociedades, aproximando-se a criança pequena do dito "homem primitivo" e fazendo coincidir o termo do desenvolvimento, na idade adulta, com o estágio de civilização do adulto das sociedades industrializadas. Nos manuais de história da educação, também se encontram referências a essa teoria, as quais costumam aparecer no capítulo inicial, dedicado à educação do "homem primitivo". A teoria da recapitulação foi apresentada como verdadeira, mas também foi questionada e mesmo contestada nos discursos de ambas as 
disciplinas, apresentando-se como objeto de controvérsia, como se verá adiante a partir do exame dos manuais.

\section{CONSIDERAÇÕES TEÓRICO-METODOLÓGICAS}

Os temas da evolução e do progresso marcaram presença na história da educação e na psicologia educacional ensinadas aos professores no decorrer do século XX e constituíram também o horizonte a partir do qual se instituíram as ciências humanas no século XIX. A psicologia, a sociologia e a antropologia se estabeleceram nesse período e adotaram a física e principalmente a biologia como modelos de ciência para a formulação de suas teorias e procedimentos de estudo. A biologia era então uma ciência transversal, cujo modelo explicativo foi adotado para explicar não apenas a natureza, mas também as sociedades e os indivíduos. O conceito de evolução tornou-se central para a descrição das transformações vividas pelas sociedades desde o dito homem primitivo até $o$ homem civilizado das sociedades ocidentais, assim como das transformações vividas pelo indivíduo da primeira infância à idade adulta, tendo sido empregado também para comparar os indivíduos considerados deficientes mentais aos indivíduos tidos como normais. Como observou Stephen Jay Gould,

A recapitulação também proporcionou um critério irresistível a todos os cientistas interessados em estabelecer diferenças hierárquicas entre os grupos humanos. Assim, os adultos dos grupos inferiores devem ser como as crianças dos grupos superiores, pois a criança representa um ancestral adulto primitivo. Uma vez que são como os meninos brancos, os negros adultos e as mulheres são também representantes vivos de um estágio primitivo da evolução dos homens brancos (GOULD, 2003, p. 113).

No âmbito da formação de professores, a psicologia se apresentava, desde o início do século XX, como a disciplina em condições de proporcionar fundamentação científica às práticas pedagógicas, ao desvendar o processo de 
desenvolvimento do indivíduo, ao explicitar as necessidades e os interesses das crianças de diferentes faixas etárias e ao permitir acessar as diferenças individuais por meio dos testes. A história, por sua vez, foi valorizada como a matéria que tornava possível aprender com a experiência do passado, de modo a evitar os erros já cometidos e tomar decisões acertadas no presente, tendo em vista preparar um futuro mais auspicioso.

Os temas da evolução e do progresso não constituíram tópicos dos programas de história da educação e de psicologia educacional, não foram objetos de um capítulo específico dos manuais, mas correspondem a uma perspectiva que atravessa os conteúdos dessas disciplinas, aproximando-as, mas também distinguindo-as, como veremos a seguir. Embora esta análise não se situe propriamente no campo da história das disciplinas escolares, beneficia-se dos trabalhos aí realizados, especialmente das reflexões presentes no texto seminal de André Chervel (1990), na medida em que se interessa pelas finalidades do ensino dessas disciplinas nos cursos de formação dos professores. Já se explicitou que a história permitia aprender com a experiência do passado para construir um futuro melhor. A psicologia consistia no estudo do aluno que proporcionava bases científicas às práticas de ensino. Ambas as disciplinas prometiam um conjunto de verdades cujo domínio conferia maior controle sobre o futuro. Tratava-se de aproveitar as experiências do passado e os conhecimentos científicos sobre a criança para favorecer o pleno desenvolvimento dos alunos do presente, os cidadãos do futuro.

A psicologia revestia-se de um interesse especial, na medida em que, como bem observou Chervel, sendo os alunos de idades diferentes, uma preocupação com a psicologia do desenvolvimento deveria estar presente no ensino de todas as matérias, tendo em vista sua adaptação ao estágio de desenvolvimento dos escolares. Se, como diz o autor, a psicologia atravessa as disciplinas escolares e diz respeito ao como ensinar alunos de determinada faixa etária, pode-se acrescentar que a história também se faz presente no conteúdo de diversas disciplinas, frequentemente merecendo um capítulo introdutório 
dos manuais dos cursos de formação docente, e diz respeito aocomo tudo começou, ao surgimento da disciplina e às iniciativas dos seus primeiros protagonistas.

A análise dos manuais empregados na formação dos professores permite uma aproximação à cultura escolar que, como bem observou Dominique Julia, não se confunde com outras culturas que lhe são contemporâneas e com as quais se relaciona - cultura religiosa, cultura política, cultura popular - mas guarda a sua especificidade. Na definição já consagrada pelo autor, a cultura escolar se refere a "um conjunto de normas que definem conhecimentos a ensinar e condutas a inculcar, e um conjunto de práticas que permitem a transmissão desses conhecimentos e a incorporação desses comportamentos" (JULIA, 2001, p. 10). Os manuais de ensino, frequentemente escritos a partir da experiência dos professores em sala de aula e destinados ao uso escolar, constituem uma fonte privilegiada para o estudo da cultura escolar, na medida em que ocupam uma posição intermediária entre as normas para o ensino de uma disciplina, expressas nos programas oficiais, e aquilo que os professores fazem e dizem em sala de aula e que raramente deixou registros, sobretudo quando se considera os períodos mais recuados da história da educação. Mesmo levando-se em conta a advertência do autor de que "o manual escolar não é nada sem o uso que dele for realmente feito, tanto pelo aluno como pelo professor" (JULIA, 2001, p. 34), pode-se admitir que o manual é um indutor de práticas, pois sugere uma sequência dos conteúdos para o ensino da matéria - ainda que essa possa não ser seguida, ainda que o professor possa pular capítulos ou não concluir o livro - e oferece orientações, exemplos, sugestões de atividades etc.

Como observou Décio Gatti, a produção acadêmica brasileira contemporânea sobre a história das disciplinas ministradas nos cursos de formação docente tem se avolumado nos últimos anos, mas as investigações têm incidido principalmente sobre as finalidades ideais do ensino, identificadas a partir da legislação, programas de ensino, periódicos educacionais e manuais. 
Por outro lado, ainda há relativamente poucos trabalhos voltados à apreensão das finalidades reais do ensino, que se aproximam das práticas em sala de aula, o que se justifica pela dificuldade de se ter acesso aos registros do que se passava no dia-a-dia da escola em cadernos escolares, exercícios, avaliações e livros de ocorrências disciplinares, os quais raramente foram preservados. (GATTI JÚNIOR, 2017). Pode-se considerar, contudo, que os periódicos educacionais, assim como os manuais de ensino, são fontes que permitem uma aproximação maior ao cotidiano escolar do que a legislação ou a obra dos grandes teóricos, o que permite considerá-los como discursos que se situam entre a cultura escolar, a produção científica e as expectativas e demandas sociais feitas à escola. Segundo Catani e Bastos, a imprensa periódica educacional pode contribuir como

(...) um guia prático do cotidiano educacional e escolar, permitindo ao pesquisador estudar o pensamento pedagógico de um determinado setor ou grupo social a partir da análise do discurso veiculado e da ressonância dos temas debatidos, dentro e fora do universo escolar (CATANI; BASTOS, 1997, p. 5).

E, conforme Vivian Batista da Silva, em sua pioneira pesquisa sobre os manuais pedagógicos,

Poderíamos, então, destacar a hierarquia construída na literatura educacional dividindo os textos em dois níveis, um mais legítimo ligado à produção de saberes teóricos - e outro mais relacionado às práticas docentes. Essa divisão estruturou os conteúdos dos manuais pedagógicos e foi reconhecida em afirmações como a de Rafael Grisi (1956), ele mesmo escritor de um manual, segundo as quais existiu uma 'pedagogia dos céus', feita pelos teóricos, em academias e bibliotecas, e uma 'pedagogia da terra', realizada pelos professores no dia a dia de suas atividades (SILVA, 2018, p. 44-45).

Nesta análise dos manuais de psicologia educacional e história da educação, segue-se a sugestão de Foucault de ater-se a um exame de superfície 
do discurso, o que quer dizer que se renuncia a procurar, além ou aquém do nível manifesto, a verdade ou o sentido oculto dos enunciados ou, atrás deles, as intenções não declaradas dos autores. Em vez disso, a partir da identificação das referências à evolução e ao progresso, busca-se estabelecer relações entre os textos no nível dos enunciados, por meio da identificação de aproximações e recorrências, ao mesmo tempo em que se busca descrevê-los em sua dispersão, reconhecendo as diferenças e divergências manifestas entre enunciados (FOUCAULT, 2004).

A análise orienta-se pelas seguintes questões: que aproximações e diferenças se pode identificar entre a história da educação e a psicologia educacional, no que diz respeito aos temas da evolução e do progresso? Esses temas foram referidos a que objetos do discurso em cada caso: tratou-se da evolução dos animais, da criança, do homem, das sociedades? Quem pôde tomar a palavra e assumir a posição de autor em uma e outra disciplina? Em dois casos apresentados adiante, os mesmos autores escreveram manuais de ambas as disciplinas: Theobaldo Miranda Santos, catedrático da Faculdade Católica de Filosofia de Santa Úrsula e do Instituto de Educação do Rio de Janeiro, e Ruy de Ayres Bello, professor catedrático da Universidade do Recife, da Universidade Católica de Pernambuco e do Instituto de Educação de Pernambuco. Que conceitos e considerações teóricas se apresentam nos seus enunciados da história da educação e da psicologia educacional quando se trata desses temas?

Tais questões foram exploradas a partir do exame dos seguintes manuais escritos por professores de história da educação e psicologia educacional, destinados à formação docente: 
Quadro 1: Manuais de Psicologia Educacional e de História da Educação considerados na análise

\begin{tabular}{|c|c|}
\hline PSICOLOGIA EDUCACIONAL & HISTÓRIA DA EDUCAÇÃO \\
\hline $\begin{array}{l}\text { BELLO, Ruy de Ayres. Introdução à psicologia } \\
\text { educacional. } 2^{\mathrm{a}} \text {. ed., Editora do Brasil, } 1964 .\end{array}$ & $\begin{array}{c}\text { BELLO, Ruy de Ayres. Pequena História da } \\
\text { Educação. Editora do Brasil, } 1962 \text { (Coleção } \\
\text { Didática do Brasil, v. 19). }\end{array}$ \\
\hline $\begin{array}{l}\text { MEDEIROS, Maurício de. Aspectos da } \\
\text { psicologia infantil. Rio de Janeiro, José } \\
\text { Olímpio, 1952. }\end{array}$ & $\begin{array}{c}\text { BRIQUET, Raul. História da Educação: } \\
\text { evolução do pensamento educacional. São } \\
\text { Paulo: Renascença, } 1946 .\end{array}$ \\
\hline $\begin{array}{l}\text { OLINTO, Plínio. Psicologia. Rio: Guanabara, } \\
1934 .\end{array}$ & $\begin{array}{l}\text { CAMPOS, Zaira de Moura. História da } \\
\text { Educação. Ribeirão Preto: Ellos, } 1972 .\end{array}$ \\
\hline $\begin{array}{l}\text { RUDOLFER, Noemy da Silveira. Introdução à } \\
\text { Psicologia Educacional. } 2^{\text {a }} \text {. ed., São Paulo: } \\
\text { Companhia Editora Nacional, } 1961 .\end{array}$ & $\begin{array}{c}\text { PEIXOTO, Afrânio. Noções de História da } \\
\text { Educação. } 3^{\mathrm{a}} \text {. ed., Companhia Editora } \\
\text { Nacional, } 1942 .\end{array}$ \\
\hline $\begin{array}{l}\text { SANTOS, Theobaldo Miranda. Noções de } \\
\text { Psicologia Educacional. Companhia Editora } \\
\text { Nacional, 1945. }\end{array}$ & $\begin{array}{l}\text { SANTOS, Theobaldo Miranda. Noções de } \\
\text { História da Educação. Companhia Editora } \\
\text { Nacional, } 3^{\text {a }} \text {. ed., } 1951 \text {. }\end{array}$ \\
\hline
\end{tabular}

Fonte: Quadro elaborado pelo/a autor/a.

\section{A PSICOLOGIA NOS MANUAIS DE HISTÓRIA E A HISTÓRIA NOS MANUAIS DE PSICOLOGIA}

A história da educação e a psicologia educacional como disciplinas independentes foram introduzidas nos currículos de formação docente ao mesmo tempo, ao lado de didática, sociologia, higiene e puericultura, na década de 1920 (ANTUNES, 2007, p. 76), período em que começava a se intensificar a divulgação dos princípios da Escola Nova no país. Na justificativa da reforma do ensino normal de Minas Gerais de 1928, Francisco Campos, então secretário do interior, afirmava que a psicologia era matéria indispensável nos currículos de formação dos professores por dar acesso aos conhecimentos sobre a criança (GUIMARÃES; GATTI JÚNIOR, 2012). Ponderava: "Si o destino da escola é a criança, o conhecimento da criança quanto mais completo mais facilitará à 
escola o exercício da sua missão" (MINAS GERAIS, 1928, p. 75). O autor acrescentava que era principalmente ao desenvolvimento da psicologia que se devia o processo em curso de renovação da escola e dos métodos de ensino.

\begin{abstract}
Si quisermos encontrar a origem de todo esse movimento, que se assemelha a um ato de despejo das velhas escolas adormecidas na sua prática e na sua rotina, deveremos nos dirigir, não aos práticos do ensino, mas aos Institutos Jean-Jacques, em Genebra, à Universidade de Bruxelas, às Universidades americanas, às Universidades e Seminários da Áustria e da Alemanha, aos psychologos, aos Kofka, aos Stern, aos Spranger, aos Claparède, aos Decroly, aos Dewey (MINAS GERAIS, 1928, p. 79).
\end{abstract}

A psicologia era associada assim à evolução dos conhecimentos e das técnicas pedagógicas, sem os quais a escola se via estagnada. Também o estudo da história da educação deveria ser feito tendo em vista a preparação do futuro por meio do bom aproveitamento da experiência do passado:

\begin{abstract}
A história da educação terá, ainda, a vantagem de incutir na inteligência dos professores a verdade, que nunca é demais repetir, de que somente a educação tornou possível a civilização do homem, que dela depende o seu presente, como dependerá o seu futuro, e que os povos que não cuidam da educação se acham, por isso mesmo, condenados a essas regressões históricas, de que não conservam a memória porque não deixaram testemunhos (MINAS GERAIS, 1928, p. 80-81).
\end{abstract}

Essa perspectiva evolutiva e progressista se reproduz nos textos dos manuais, quando se trata de apresentar as contribuições dessas disciplinas para a educação escolar. À história caberia estabelecer a verdade sobre os fatos passados, trazer a experiência acumulada no tempo para ser aproveitada na produção do futuro. A psicologia tinha a oferecer a verdade científica sobre a evolução da criança, permitindo adequar as práticas escolares à sua natureza, tornando o ensino mais eficiente e evitando o desperdício de tempo. Em Noções de História da Educação (1942), Afrânio Peixoto, professor da Universidade do 
Rio de Janeiro, defendia o estudo da disciplina nos seguintes termos:

A educação olha o futuro, nossa preocupação, tentando o aperfeiçoamento dos órgãos desse imenso e imortal organismo, que é a sociedade. Se é problema a resolver na escola ativa da vida o futuro humano, ele só pode ser resolvido com a experiência anterior do passado humano. É a justificação, educativa, pedagógica, do estudo dessa história da educação (PEIXOTO, 1942, p. 10).

A uma educação perfeita corresponderá uma vida feliz, dos homens e da humanidade: é o futuro, o ideal. Como se vem preparando - do passado ao presente, é a história da educação (PEIXOTO, 1942, p. 15).

Em Psicologia (1934), Plínio Olinto, psiquiatra da Assistência a Psicopatas e professor da disciplina no Instituto de Educação, assim se pronunciava sobre a sua contribuição para a educação:

(...) é principalmente sobre os princípios de educação que ela vem influindo progressivamente. É sobre as bases da pedagogia que ela concentra as suas conclusões, pois toda a moderna organização da escola do trabalho repousa sobre as observações da psicologia.

Quantos erros cometeu a pedagogia por falta de psicologia?

Quem poderá ensinar crianças sem lhes conhecer a mentalidade? (OLINTO, 1934, p. 15).

No programa para as escolas normais formulado a partir da Reforma do Ensino Normal de Minas Gerais em 1928, o programa de história da educação apresenta 25 pontos e há referência à psicologia no ponto XVIII, que trata do início dos cursos normais. Na íntegra, esse ponto do programa que se refere à psicologia é o seguinte:

XVIII - Os começos da instrução normal. A contribuição de Pestalozzi. Desenvolvimento do ensino oral e objetivo. O moderno ensino normal. O Ensino normal da França, na Alemanha, na Bélgica, nos Estados Unidos, na Áustria, no Brasil e, particularmente, no Estado de Minas Gerais. A expansão do ensino normal. A psicologia 
Segue-se ao programa de história da educação o de psicologia educacional. Nele não há um capítulo dedicado à história, mas uma atenção privilegiada às mudanças ocorridas ao longo do tempo, em perspectiva evolutiva, a qual atravessa a matéria. $\mathrm{O}$ segundo ponto do programa para o primeiro ano, dedicado ao estudo do tema "A psicologia e a educação" consiste em "A evolução biológica do homem e a evolução sociológica do homem" e tem o seguinte conteúdo:

O homem como ser vivo e como ser social. Instintos. Caracteres hereditários. Tendências egoístas e tendências sociais. O homem e o meio. Adaptação ao meio. Imitação. Influências do meio sobre o homem e do homem sobre o meio. O meio cósmico e o meio social. A evolução biológica e a evolução sociológica do homem (MINAS GERAIS, 1928, p. 284).

A partir do exame dos manuais de história da educação, observa-se que os capítulos seguem a ordem cronológica da História Geral: Povos primitivos, Antiguidade, Idade Média, Renascimento, Idade Moderna, Idade contemporânea, com um ou mais capítulos finais dedicados à história da educação no Brasil. E o conteúdo se desenvolve a partir da apresentação dos autores, suas ideias e propostas pedagógicas. Trata-se de história da civilização, mas também de "evolução do pensamento educacional", subtítulo do livro de Raul Briquet.

Em alguns deles (Raul Briquet, 1946; Theobaldo Miranda Santos, 1951, Ruy de AyresBello, 1962) a "educação psicológica" aparece como um capítulo, que corresponde ao período do final do século XVIII à primeira metade do século XIX e aos autores Froebel, Herbart e Pestalozzi. Nesses livros, o capítulo dedicado à educação psicológica é anterior àquele dedicado à "educação científica", de que são representantes Herbert Spencer, teórico do 
evolucionismo e Comte, da segunda metade do século XIX. Esse aspecto da estruturação dos manuais surpreende, quando se leva em conta que nos compêndios de psicologia educacional, a psicologia é apresentada como a disciplina que pode proporcionar bases científicas para a pedagogia e teve início quando Wundt criou o primeiro laboratório de psicologia na Universidade de Leipzig, Alemanha, em 1879. Assim, o exame conjunto dos manuais das duas disciplinas evidencia diferenças nos modos de se referir às relações entre psicologia e a educação. Os manuais de história da educação dedicam um capítulo à emergência histórica de propostas pedagógicas que trazem uma preocupação com a psicologia da criança a partir de meados do século XVIII, com Pestalozzi, Herbart e Froebel, que são referidos como representantes da "educação psicológica" ou de uma "pedagogia de sentido psicológico" como período específico da história da educação. Já os manuais de psicologia educacional, quando fazem referência à história da disciplina, consideram como seu início não o surgimento de uma pedagogia devotada à psicologia da criança, mas a criação do laboratório de psicologia experimental por Wundt. Esse aspecto chama ainda mais atenção quando se manifesta em manuais das duas disciplinas escritos pelo mesmo autor, como é o caso de Theobaldo Miranda Santos.

Noções de História da Educação contém um capítulo intitulado "A educação psicológica", no qual apresentam-se os "educadores psicológicos" representativos dessa fase, que viveram de meados do século XVIII a meados do século XIX: Pestalozzi (1746-1827); Herbart (1776-1841) e Froebel (1782-1852). Sobre "a tendência psicológica na educação" o autor esclarece que

Com o raiar do século XIX, a influência da psicologia sobre a educação, isto é, a preocupação de fazer o trabalho educativo gravitar em torno do espírito da criança, começa a ganhar terreno. Indubitavelmente a obra de Rousseau muito concorreu para que essa tendência se afirmasse e desenvolvesse. A educação psicológica representou mesmo uma tentativa de dar aos princípios do naturalismo pedagógico do mestre de Genebra uma formulação científica e um caráter de processo escolar prático (SANTOS, 1951, P. 
334).

O mesmo se passa na Pequena História da Educação, de Ruy de Ayres Bello. O capítulo intitulado “A Pedagogia de sentido psicológico” inicia-se como segue:

Graças à influência de Rousseau, que havia insistido na necessidade de se basear o processo educativo nas peculiaridades mentais da criança, começaram os pedagogos e educadores a se preocupar com o estudo sistemático da natureza infantil, como ponto de partida para o desenvolvimento de suas teorias e atividades educativas. Essa preocupação aparece em todos os pedagogos de qualquer modo influenciados pelas teorias do Emílio, mas é principalmente em Pestalozzi e em seus discípulos Herbart e Froebel que ela é levada às últimas consequências. (BELLO, 1962, p. 196).

A partir do exame conjunto dos seus manuais de história da educação e de psicologia educacional identifica-se, portanto, um desnível entre a educação psicológica como período da história da educação em que emerge o interesse pela formulação de métodos de ensino adaptados às características e necessidades da criança e a psicologia educacional, como ciência aplicada que passaria a compor o currículo de formação dos professores. Esse desnível se manifesta tanto na cronologia, como na relação dos autores associados e no conteúdo do discurso.

Na introdução de seu manual dedicado à psicologia educacional, Theobaldo Miranda Santos se refere a autores que viveram a partir de meados do século XIX que se dedicaram à psicologia experimental, dentre os quais Wundt, Stanley Hall, Claparède, Betscherew, Pavlov, Binet e Simon etc. como pioneiros da psicologia. Enquanto em seu manual de história da educação, os capítulos se organizam a partir da apresentação dos autores e suas ideias pedagógicas em sequência cronológica, no manual de psicologia educacional estrutura-se a partir da descrição esquemática da disciplina como ciência: observação, experimentação, aparelhos, métodos. 
Em sua Introdução à psicologia educacional, Ruy de Ayres Bello, por sua vez, faz os primórdios da psicologia recuarem a Platão e afirma que Aristóteles é "considerado o verdadeiro fundador da Psicologia, indicando o seu objeto e o seu método e usando pela primeira vez esse nome" (1962, p. 23). Para esse autor, os estudos dessa disciplina aplicados à educação atingem o auge no século XX, designado o século da criança, com a ampliação e a intensificação dos trabalhos levados a efeito por Binet e Simon, Stern, Muller, Lippman, Decroly, De Sanctis, Claparède, Dewey, Thorndike, Ballard e outros.

Já em História da Educação (1972) de Zaíra de Moura Campos, professora de história da educação da Faculdade de Filosofia, Ciências e Letras da Universidade Moura Lacerda, em Ribeirão Preto, há um tópico intitulado "Pedagogia psicológica e experimental”, o qual está incluído no penúltimo capítulo da obra "A Pedagogia do século XX". Trata-se de um tópico sumário, no qual a autora explica o seguinte:

\footnotetext{
A pedagogia psicológica é produto de nosso tempo. Entretanto, bem antes do século, já se fizeram importantes observações psicológicas sobre o desenvolvimento da criança (Rousseau).

Mas, num estudo mais científico da criança e sua aplicação à educação, data do fim do século XIX, começo do século XX (CAMPOS, 1972, p. 171).
}

Nesses termos, a pedagogia psicológica referida pela autora já não corresponde àquela apresentada nos livros de Raul Briquet (1946); Theobaldo Miranda Santos (1951), Ruy de Ayres Bello (1962), mas à pedagogia associada à psicologia experimental, aproximando-se assim do discurso dos manuais de psicologia educacional considerados, dentre os quais o de Plínio Olinto, quase quatro décadas anterior, para quem a psicologia tornou-se moderna ao se separar da filosofia e aproximar-se da biologia:

Os estudos modernos tendem a dar a psicologia uma orientação mais firme, mais concreta, ou, pelo menos, desviá-la do caminho das 
cogitações abstratas onde ela se debateu por muito tempo, vaga, indecisa, fazendo corpo comum com a filosofia.

Os psicólogos modernos resolveram aproximá-la mais da biologia e os resultados foram animadores. (OLINTO, 1934, p. 14).

A propósito do manual de Plínio Olinto, vale observar que, enquanto nos manuais de história de Briquet, Santos e Bello, a educação psicológica correspondia a um intervalo da linha do tempo da história da educação, nesse livro as diferentes épocas históricas se distinguem pela valorização social de um atributo psicológico específico, como segue:

A sociedade também sujeita a seus ritmos põe em destaque, periodicamente, certos tipos como padrões da época.

Quando a força foi a qualidade mais apreciada pelos homens, apareceram os heróis; quando a bondade floresceu, tivemos os tempos dos santos; no período da cultura, vieram os sábios, ultimamente os homens de ação se notabilizam.

Ford passa a ser um símbolo da época.

Lutadores, místicos, pensadores, idealistas, contemplativos, cederam lugar aos utilitaristas. (OLINTO, 1934, p. 267).

Merece menção especial o livro Introdução à Psicologia Educacional, de Noemy da Silveira Rudolfer, professora de psicologia na Escola Normal Caetano de Campos e posteriormente na Universidade de São Paulo, pois corresponde a uma história da disciplina psicologia educacional. Nesse compêndio, os capítulos referem-se aos diferentes períodos de desenvolvimento da matéria, em vez de se dedicarem à exposição dos diferentes aspectos do funcionamento psicológico - hábito, atenção, afetividade, inteligência, linguagem etc. - como é típico nos manuais do gênero. Esse livro original é resultado de tese elaborada pela autora por ocasião do seu concurso de ingresso na USP e foi motivado pela sua necessidade de se orientar entre as diferentes teorias, conforme ela registrou no prefácio: 


\begin{abstract}
No início dos meus estudos, a despeito da orientação firme de meus mestres, foi sempre de perplexidade o estado de espírito com que me aventurei na leitura de qualquer obra no campo da Psicologia, tão grande era o senso das diferenças de pontos de vista e tão intensa a compreensão de que o aceitar uma doutrina ou, melhor, o filiar-se a uma escola seria por em risco a objetividade necessária nos domínios da Psicologia. Foi natural, portanto, que, em resultado, o estudo da história da Psicologia, como indispensável, me atraísse profundamente. Três conclusões tirei desse estudo: em primeiro lugar, a de que, na multiplicidade de orientações psicológicas, só um ponto de vista eclético pode ser de auxílio; em segundo, a de que $a$ compreensão das psicologias modernas depende de uma compreensão da evolução histórica dessa ciência; e finalmente, a de que apenas dois critérios parecem garantir a busca do melhor em Psicologia - o emprego do método científico e a fertilidade no decorrer dos tempos (RUDOLFER, 1961, p. XV-XVI). (destaques nossos).
\end{abstract}

Diversas foram as associações entre a história da educação e a psicologia educacional, assim como as expressões empregadas pelos autores para se referir a essas associações, como se pode observar a partir do exame desse conjunto de livros. Nos manuais de história, é recorrente a apresentação de uma educação psicológica que corresponde ao período em que o estudo da criança adquire centralidade no pensamento educacional. Nos manuais de psicologia educacional, era frequente recorrer-se à história para destacar a própria psicologia como ciência moderna, sob o pano de fundo das especulações filosóficas. Em comum, ambas as disciplinas alinhavam experiência, ciência, evolução e progresso como vetores que indicavam o horizonte da educação.

\title{
EVOLUÇÃO E PROGRESSO NOS MANUAIS DE HISTÓRIA DA EDUCAÇÃO E PSICOLOGIA EDUCACIONAL
}

Três dos seis manuais de história da educação examinados dedicam um capítulo inicial à apresentação da "educação primitiva" ou "educação dos selvagens e primitivos”, enquanto os demais desconsideram esse tema e iniciam 
pela Grécia Antiga. A leitura conjunta dos capítulos sobre a educação dos primitivos nos manuais evidencia um aspecto da controvérsia entre educadores pioneiros e católicos referida no início do texto, quando se trata do evolucionismo e da teoria da recapitulação. Afrânio Peixoto, signatário do Manifesto dos Pioneiros da Educação Nova, afirmava que pouco se sabia sobre os povos selvagens e primitivos, mas muito se especulava sobre a bondade ou maldade original do homem no âmbito das religiões e da filosofia. Acerca da teoria da recapitulação, o autor ponderava:

as crianças não são reduções humanas de adultos, como os selvagens não são homens apenas menos educados de outrora. As crianças têm órgãos que lhes fazem o desenvolvimento, outros que se aperfeiçoam, outros que, já sem função, deperecem mais tarde... O adulto é o que resulta, outro ser, saído do primeiro, como o fruto da flor, sequência, e não múltiplo (PEIXOTO, 1942, p. 10)

Apesar disso, aproximava a criança do selvagem ao se referir à sua mentalidade pré-lógica, assim como aproximava o selvagem dos animais no que dizia respeito à adaptação ao meio ambiente e ao expressivo desenvolvimento dos sentidos que uns e outros apresentavam:

O selvagem está num período rudimentar de mentalidade em que a relação entre as cousas é mística, é metafísica, é pré-lógica (não "antilógica" ou "ilógica"), diz Levy-Bruhl, cuja filosofia (1910) esclarece estes assuntos. Jean Piaget renova a psicologia infantil, seguindo-lhe as pegadas, estudando o pensamento simbólico, de primitivo infantil, pré-lógico (PEIXOTO, 1942, p. 11).

A educação selvagem é apenas uma adaptação ao ambiente. Como o ambiente não muda, diz Monroe, a educação ficará estacionária, donde, afirmara Spencer, a imprevisão primitiva. A dinâmica educacional cultiva, pela didática psicológica, as faculdades perceptivas: os sentidos têm como em certos animais, acuidade notável (PEIXOTO, 1942, p. 12).

Theobaldo Miranda Santos e Ruy de Ayres Bello, representantes dos 
educadores católicos, expressavam a sua discordância em relação a esses aspectos, recusando as teses biológicas da recapitulação e do evolucionismo. Bello entendia que Tristão de Athayde (Alceu Amoroso Lima), "tendo considerado todos os modernos ensinamentos científicos sobre a mentalidade primitiva, pôde chegar a uma conclusão que admiravelmente sintetiza tudo o que a ciência moderna realmente estabeleceu a respeito" (1962, p. 10) e em seguida apresentava uma citação desse autor que já aparecia registrada no manual de Santos na década anterior:

\begin{abstract}
'Mostraram-se estas, conclui Tristão de Athayde, à luz de uma observação verdadeiramente científica, já não mais modelos de inocência e pureza, nem criaturas ainda animalizadas. E sim raças inferiores, em civilização material e progresso moral, mas perfeitamente humanas, cuja história possui variações muito ricas, cuja evolução é muito complexa, cuja psicologia possui uma relativa riqueza e cujas instituições estão longe de ter sofrido a marcha progressiva, delineada por observações insuficientes e conclusões precipitadas' (apud BELLO, 1962, p.10 e SANTOS, 1951, p. 29).
\end{abstract}

Ruy de Ayres Bello, ao tratar as fontes históricas da educação "primitiva”, explicava que os estudiosos buscavam obter informações sobre as sociedades "primitivas" por meio dos vestígios deixados por elas e a partir da observação dos "selvagens" contemporâneos. Em seguida referia-se às críticas já realizadas a esse método por, entre outros, Robert Lowie, professor da Universidade da Califórnia, segundo o qual "mesmo os grupos culturais mais singelos da atualidade, contam com um longo passado, tendo por isso, progredido muitíssimo desde o seu estádio inicial de civilização" (apud BELLO, 1962, p. 12). Apesar disso, considerava que os estudos sobre a educação do homem "primitivo" a partir da análise das práticas educativas dos "selvagens" contemporâneos tinham "uma significação analógica":

Diz Roger Gal que os selvagens modernos nos oferecem 'uma imagem dos grupos sociais onde nenhuma instituição especializada era designada para a educação dos jovens', o que quer dizer, onde a 
educação se apresentaria sob a sua forma mais simples, talvez apenas esboçada. Por esse modo, se põe a questão nos seus justos termos que, em síntese, vêm a ser os seguintes: mesmo que os selvagens atuais não sejam mais primitivos, a educação entre eles praticada é, provavelmente a educação primitiva, isto é, a educação na sua forma mais singela, mais rudimentar. Dessa maneira, poderemos, utilizando o processo da analogia, que é sempre hipotético, partir da observação do fato educacional, tal como ocorre entre os selvagens contemporâneos, cuja vida social nos oferece, pelo menos, uma 'imagem' dos grupos primitivos, para o estudo das formas mais rudimentares, e, de certo modo, embrionárias, da educação (BELLO, 1962, p. 13).

No livro de Afrânio Peixoto, chama atenção o preconceito em relação aos negros na mesma passagem em que se procura negar o determinismo biológico. Isso se manifesta no capítulo sobre a educação dos primitivos, quando o autor se refere à aplicação de testes de inteligência em crianças negras na África do Sul e Austrália. Embora afirme não haver diferença "natural" de desempenho, manifesta-se no seu texto a associação entre criança negra e homem "primitivo", assim como a hierarquização de culturas:

Contudo, um fato a reter: tests de inteligência aplicados na Austrália e na África do Sul às crianças negras mostraram que não são inferiores aos meninos brancos. Todas as crianças, não importa as raças, são bem dotadas, graças a bons olhos e bons ouvidos que captam a vida; depois é que é... a doença em uns, uma sociedade amorfa na generalidade, um ensino, dogmático nos meios educados, fazem o resto - a desigualdade "racial" do mundo, que é mais "humana", que "natural" (PEIXOTO, 1942, p. 13).

A História da Educação, escrita por Raul Briquet, professor da Faculdade de Medicina da USP e professor de "Educação Nacional" da Escola Livre de Sociologia e Política de São Paulo, não apresenta um capítulo sobre a educação "primitiva”, mas em seu capítulo “A educação científica”, refere-se à teoria da recapitulação, ao tratar da proposta pedagógica de Spencer: "A educação da criança deve ajustar-se ao modo e à ordem seguida pela evocação da humanidade, consideradas do ponto de vista histórico" (BRIQUET, 1946, p. 
139). Ao tratar da contribuição de Spencer, o autor afirma: "O mérito da educação espenceriana está em ter pregado, já em 1855, nos seus Princípios de Psicologia, a importância dessa ciência indispensável para se edificar a teoria científica da educação" (idem, p. 141), explicitando assim de uma outra maneira a presença da psicologia no discurso da história da educação destinada à formação docente: a descoberta da importância da psicologia para a educação como um acontecimento ou um feito registrado na história da educação.

Em Introdução à psicologia educacional, livro no qual Noemy Silveira Rudolfer discorre sobre a história da disciplina, apresenta-se um enunciado recorrente no discurso dos manuais do gênero, segundo o qual foi no século XIX que a psicologia se tornou científica, ao aproximar-se da biologia, particularmente do evolucionismo. Para Noemy Rudolfer, foi então que a disciplina adotou um método experimental e passou a empreender estudos sobre o psiquismo animal que levaram à formulação de teorias da aprendizagem, bem como às investigações sobre o psiquismo inato e as diferenças individuais (RUDOLFER, 1961, p. 74). A autora afirmava que Spencer antecipou-se a Darwin na divulgação do evolucionismo e contribuiu tanto para a sua aceitação na psicologia como para o surgimento da "psicologia genética, comparativa e diferencial", ajudando a tornar evidente a necessidade de levar em conta o fator do desenvolvimento na educação. Acrescentava que a teoria evolucionista de Darwin teve três consequências importantes para a psicologia: uma ênfase na comparação interessada em demonstrar a evolução psíquica; uma atenção às diferenças individuais, tendo em vista a identificação do mais apto e o estudo do desenvolvimento individual com o objetivo de estabelecer suas relações com o desenvolvimento da espécie. Sintetizava afirmando que "A psicologia comparativa, a diferencial e a genética são filhas do evolucionismo" (RUDOLFER, 1961, p. 83). Em seu livro, como em outros manuais, a referência à teoria da recapitulação aparece associada ao tema dos jogos e ao nome de Stanley Hall que, conforme a autora, formulou uma teoria atávica: 


\begin{abstract}
Nos primeiros dias do darwinismo, Haeckel mostrara que o embrião humano passa por estádios que se assemelham àqueles pelos quais a raça passou; formula, assim, em 1866, a lei biogenética - a embriogênese repete a filogênese. (...) Darwin e Spencer tinham, ao mesmo tempo, dado origem a numerosas teorias relativas à evolução cultural pela qual passaram as sociedades humanas. Sobre esses fundamentos, Hall expõe no seguinte princípio essa herança: a criança passa por uma série de estádios semelhantes aos da vida da espécie. Passa, como a espécie, por um período de caça, de construção, de coleção, de pastoreio. Igualmente, interpreta os jogos da criança como sendo o exercício daquelas atividades próprias ao estádio cultural a que corresponde o seu próprio estádio. A educação, portanto, deve, no seu entender, consistir em oferecer-se à criança as oportunidades para expansão desses impulsos característicos de cada época de desenvolvimento, com o seu ciclo inevitável de instintos e de interesses. Foi da psicologia comparativa que ele tirou a noção de evolução dos instintos, assim como colheu, da biologia, a teoria da recapitulação (RUDOLFER, 1961, p. 142).
\end{abstract}

Deve-se notar, porém, que, assim como na história da educação, na psicologia educacional a teoria da recapitulação foi objeto de controvérsia. Em Psicologia (1934), de Plínio Olinto, aparecia como expressão da verdade: "E cada um repete, nos limites de suas possibilidades, o esforço que empregou a humanidade na sua socialização, pois é sabido que o indivíduo refaz, abreviadamente, a marcha geral da evolução da espécie” (OLINTO, 1934, p. 254). Em Aspectos da psicologia infantil (1952), de Maurício de Medeiros era apresentada como lei: "Há uma lei em biologia que sintetiza o resultado de longas observações. Segundo essa lei a evolução do indivíduo reproduz abreviadamente a evolução da espécie. Em termos mais bombásticos, porque científicos, se diz: 'a ontogênese reproduz a filogênese’”. (MEDEIROS, 1952, p. 39). O autor recorria à teoria da recapitulação para explicar a atividade imaginativa das crianças pequenas, comparando-a à dos povos primitivos: “A observação dos povos primitivos neles assinala uma tendência ao raciocínio por analogia, tal como na criança civilizada. Essa tendência os leva a animar o mundo material que os cerca, isto é, a emprestar vida e sentimento às coisas" (MEDEIROS, 1952, p. 43). Por outro lado, como já foi dito a propósito da história da educação, os educadores Theobaldo Miranda Santos e Ruy de Ayres 
Bello punham em dúvida a teoria da recapitulação. Em seu livro Noções de psicologia educacional, Santos formulava o seguinte questionamento:

Stanley Hall subordina o jogo à lei biogenética, segundo a qual 'a ontogênese resume a filogênese'. Para ele, o jogo representa o vestígio de atividade ancestral cujo exercício é necessário ao desenvolvimento infantil; é o caso, entretanto, de se perguntar a Stanley Hall se o homem primitivo brincava de automóvel, de avião, etc., como fazem atualmente as crianças (SANTOS, 1945, p. 134).

De modo muito semelhante, Ruy de Ayres Bello também expressava a sua descrença na teoria, ao tratar da questão do jogo. Em suas palavras:

Dentre as teorias que pretendem explicar o jogo pelo passado, está a de Stanley Hall, que liga a atividade lúdica à 'lei biogenética' de Haeckel. Segundo essa lei, a evolução do indivíduo recapitularia a evolução da espécie. O jogo seria então, uma revivescência de certas formas de atividade das sociedades primitivas, tornadas caducas, em face da evolução da humanidade.

Essa explicação do jogo pode, talvez ser aceita por todos aqueles que admitem a teoria da recapitulação, mas essa teoria é apenas, uma hipótese, que tem, aliás, contra si a opinião da maioria dos cientistas (BELLO, 1964, p. 99).

Apesar das restrições formuladas ao evolucionismo à teoria da recapitulação, Theobaldo Miranda Santos não deixava de formular a sua própria versão do desenvolvimento individual associado à evolução, ao dizer:

A criança e o adolescente possuem, em germem, todas as virtualidades do adulto, porém, sob uma forma própria, que poderá variar a cada momento do seu desenvolvimento e modificar-se sob a influência do meio e da educação. A criança e o adolescente devem ser, portanto, considerados como seres em contínua evolução, em lenta mas progressiva ascensão à maturidade psíquica do adulto (SANTOS, 1945, p. 142). 
Segundo a concepção do autor, a educação tinha o poder de alterar o curso do desenvolvimento das crianças e dos adolescentes, de modo que cabia aos adultos encarregados da sua educação direcioná-los, tendo em vista os fins mais elevados da educação (SANTOS, 1945, p. 143).

A análise conjunta dos manuais evidencia que, embora os temas associados da evolução e do progresso sejam recorrentes, o evolucionismo e a teoria da recapitulação eram objetos de controvérsia. O ponto central do debate era a aproximação que se estabelecia no evolucionismo entre a criança e as culturas ditas "primitivas" e os animais. Enquanto essa aproximação era confirmada em parte dos manuais, foi recusada pelos educadores católicos, que realçavam a essência humana presente na criança e no homem "primitivo" desde o início, por meio da qual estabeleciam a sua separação do reino animal. O exame deste conjunto de manuais não permite, contudo, estabelecer uma simples oposição entre católicos e escolanovistas quanto às concepções de evolução e progresso. Isso porque houve educadores partidários da educação laica que, embora endossassem o evolucionismo, também fizeram restrições à teoria da recapitulação, como se procurou mostrar a partir da descrição do manual de história da educação de Afrânio Peixoto. Essas restrições diziam respeito, sobretudo, à continuidade que essa teoria estabelecia entre a criança $\mathrm{e}$ o adulto, entre o homem "primitivo" e o homem "civilizado". Questionavam-se essas pressuposições, chamando-se atenção para as particularidades da criança em face do adulto, assim como observando-se que o chamado homem "selvagem", vivendo no mundo contemporâneo, não correspondia ao passado do homem "civilizado", já que também o seu modo de existência se alterara com a passagem do tempo. Sendo assim, era apenas por "analogia" que se admitia procurar compreender as formas de educação do passado remoto por meio da observação das práticas dos "selvagens" contemporâneos.

A oposição entre católicos e escolanovistas também não foi total, pois, apesar da controvérsia em torno do ponto específico da aproximação entre os seres humanos considerados menos desenvolvidos e os animais, era comum nos 
discursos de uns e outros a associação entre desenvolvimento, civilização e progresso, assim como era compartilhada a convicção de que a educação cientificamente fundamentada podia promover tanto o desenvolvimento da criança como o progresso da sociedade.

\section{CONSIDERAÇÕES FINAIS:}

A associação entre educação, ciência e progresso, recorrente no discurso educacional da Primeira República e no Manifesto dos Pioneiros da Educação Nova manifestou-se também no conteúdo dos manuais da história da educação e da psicologia educacional considerados neste artigo. Nos manuais de história da educação, a educação psicológica aparecia como um período da história da educação, situado a partir de meados do século XVII, quando se manifestava na pedagogia a preocupação com a criança e o seu desenvolvimento. Nos manuais de psicologia educacional, costumava-se privilegiar a emergência da psicologia experimental, a partir da segunda metade do século XIX, como período de surgimento da disciplina.

Considerava-se que tanto a psicologia como a história tinham as suas próprias contribuições a oferecer à educação do futuro, ou à preparação do futuro por meio da educação. A história era valorizada porque permitia aprender com a experiência e evitar os erros do passado. A psicologia era necessária para dar respaldo científico às práticas educativas. Na história, a perspectiva progressista aparecia associada ao evolucionismo quando se tratava da tentativa de reconstituir a experiência educativa dos povos do passado mais remoto, designados como "primitivos". Na psicologia apresentava-se quando se procurava descrever o desenvolvimento da criança, do início à fase adulta.

Apesar da controvérsia entre católicos e escolanovistas quanto à propriedade de se estabelecer uma aproximação entre a criança, o "selvagem" ou "primitivo" e os animais, e dos questionamentos feitos à teoria da 
recapitulação por representantes das duas vertentes, a perspectiva progressista que levava a hierarquizar indivíduos e sociedades, estabelecendo uma linha evolutiva da criança ao adulto e do "primitivo" ao civilizado caracteriza o conjunto dos livros examinados.

A psicologia educacional evolutiva, se, por um lado, contribuiu para evidenciar a necessidade de adaptar o ensino às idades dos alunos, por outro lado serviu de argumento para a defesa do oferecimento de ensinos desiguais, adaptados às suas (im)possibilidades. Desse modo, frequentemente, concorreu para o aprofundamento das desvantagens dos grupos socialmente desfavorecidos, cujas crianças foram quase sempre avaliadas como menos desenvolvidas. A história da educação evolutiva, se, por um lado, pretendeu proporcionar aos professores acesso à experiência acumulada, contribuindo para que se evitassem os "erros" do passado, por outro lado, procurou estabelecer de antemão a orientação do porvir, eventualmente restringindo as possibilidades de se vislumbrarem outras alternativas de futuro.

\section{FONTES:}

BELLO, Ruy de Ayres. Pequena História da Educação. São Paulo: Editora do Brasil, 1962.

BELLO, Ruy de Ayres. Introdução à Psicologia Educacional. $2^{\mathrm{a}}$. ed., São Paulo: Editora do Brasil, 1964.

BRIQUET, Raul. História da Educação: evolução do pensamento educacional. São Paulo: Renascença, 1946.

CAMPOS, Zaira de Moura. História da Educação. Ribeirão Preto: Ellos, 1972.

MEDEIROS, Maurício de. Aspectos da psicologia infantil: e vários outros temas de psicologia e psiquiatria. Rio de Janeiro: José Olímpio, 1952.

OLINTO, Plínio. Psicologia. Rio de Janeiro: Editora Guanabara, 1934. 
PEIXOTO, Afrânio. Noções de História da Educação. $3^{\text {a }}$. ed. São Paulo: Companhia Editora Nacional, 1942.

RUDOLFER, Noemy da Silveira. Introdução à psicologia educacional. $2^{\mathrm{a}}$. ed., revista e aumentada. São Paulo: Companhia Editora Nacional, 1961 (Atualidades Pedagógicas, 30).

SANTOS, Theobaldo Miranda. Noções de História da Educação. $3^{\mathrm{a}}$. ed. São Paulo: Companhia Editora Nacional, 1951 (Curso de Psicologia e Pedagogia, 2).

SANTOS, Theobaldo Miranda. Noções de Psicologia Educacional. $3^{\text {a }}$. ed., São Paulo: Companhia Editora Nacional, 1951.

\section{REFERÊNCIAS:}

ANTUNES, Mitsuko Aparecida Makino. A Psicologia no Brasil: leitura histórica sobre sua constituição. São Paulo: Unimarco/Educ, 2007.

CARVAlHO, Marta Maria Chagas de. A escola e a República. São Paulo: Brasiliense, 1989.

CHERVEL, André. História das disciplinas escolares: reflexões sobre um campo de pesquisa. Teoria \& Educação, Porto Alegre, n. 2, p. 177-229,1990.

CATANI, Denice Barbara; BASTOS, Maria Helena Câmara. Educação em Revista: a imprensa periódica e a história da educação. São Paulo: Escrituras, 1997.

FOUCAULT, Michel. A arqueologia do saber. 7a. ed., Rio de Janeiro: Forense Universitária, 2004.

GUIMARÃES, Rosângela.; GATTI JÚNIOR, Décio. A institucionalização da disciplina História da Educação na Escola Normal mineira na primeira metade do século XX. Educação, Pontifícia Universidade Católica do Rio Grande do Sul, Porto Alegre, v. 35, n. 1, p. 54-65, jan./abr. 2012.

GATTI JÚNIOR, Décio. O Ensino de História da Educação no Brasil: fontes e métodos de pesquisa. Cadernos de História da Educação,Editora da Universidade Federal de Uberlândia, Uberlândia, v. 16, n. 1, p. 64-88, jan./abr. 2017.

GOULD, Stephen Jay. A falsa medida do homem. São Paulo: Martins 
Fontes, 2003.

GOUVÊA, Maria Cristina; GERKEN, Carlos Henrique de Souza.

Desenvolvimento humano: história, conceitos e polêmicas. São Paulo:

Cortez, 2010.

JULIA, Dominique. A Cultura Escolar como Objeto Histórico. Revista

Brasileira de História da Educação. Sociedade Brasileira de História da Educação, Universidade Estadual de Maringá, 1, jan./jun. 2001.

MANIFESTO DOS PIONEIROS DA EDUCAÇÃO NOVA (1932) Fernando de Azevedo et al. Recife: Fundação Joaquim Nabuco, Editora Massangana, 2010.

MINAS GERAIS. Decreto 8162 de 20/01/1928 - Regulamento do Ensino Normal.

SILVA, Vivian Batista da. Saberes em viagem nos manuais pedagógicos: construções da escola Portugal e no Brasil (1870-1970). São Paulo: UNESP, 2018.

VIDAL, Diana Gonçalves. 80 anos do Manifesto dos Pioneiros da Educação Nova: questões para debate. Educação \& Pesquisa, São Paulo, v. 39, n. 3, p. 577-588, jul./set. 2013 .

ANA LAURA GODINHO LIMA é professora da Faculdade de Educação da Universidade de São Paulo. Doutora em Educação pela FEUSP, com estágio de pesquisa realizado na Universidade de Wisconsin-Madison.

E-mail: alglima@usp.br

(1) https://orcid.org/0000-0003-4154-0858 
REVISTA HISTÓRIA DA

Revista História da Educação (Online), 2019, v. 23: e93208 DOI: http://dx.doi.org/10.1590/2236-3459/93208

e-ISSN: 2236-3459 http://seer.ufrgs.br/asphe 